\title{
PERANCANGAN BUKU ILUSTRASI KESEHATAN UNTUK WANITA KARIR
}

\author{
Siti Hardini ${ }^{1}$, Yanuar Rahman ${ }^{2}$ \\ ${ }^{1,2}$ Prodi S1 Desain Komunikasi Visual, Fakultas Industri Kreatif, Universitas Telkom \\ farahlsmana@gmail.com ${ }^{1}$, vidiyan@gmail.com²
}

\begin{abstract}
Abstrak
Rutinitas masyarakat dalam bekerja dapat menjadikan kurangnya perhatian masyarakat terhadap pola hidup. Kurangnya aktivitas fisik, kebutuhan gizi yang belum terpenuhi, istirahat yang tidak teratur dan lainnya dapat menimbulkan gangguan kesehatan khususnya pada wanita serta mempengaruhi produktivitas dalam bekerja. Hal inilah yang akan dibahas dalam karya ini. Perancangan menggunakan buku kesehatan dalam mengajak kalangan pekerja menjalani hidup sehat. Konten dan ilustrasi disesuaikan agar dapat menyampaikan pola hidup sehat dengan menyenangkan. Observasi, studi pustaka, wawancara serta kuesioner dilakukan sebagai metode dalam mengumpulkan data serta metode matriks dalam menganalisis buku. Buku kesehatan ini diharapkan dapat mengajak masyarakat khususnya kalangan wanita karir untuk tetap menjaga pola hidupnya dengan baik, sehingga dapat mengurangi resiko terkena penyakit dan dapat bekerja secara produktif.
\end{abstract}

Kata Kunci: ilustrasi, gaya hidup, kesehatan, wanita karir

\begin{abstract}
The work routines of the society would cause the lack of attention towards the lifestyle of the society. Lack of physical activities, nutritional needs that have not been fulfilled, irregular break, etc. may cause health problems especially for women as well as affecting productivity at work. This is what will be discussed in this work. Design of healthy book in order to engage the workers to live a healthy life. The contents and illustrations will be suitable in order to deliver the healthy lifestyle delightfully.Observation, literature studies, interviews, and questionnaires were conducted as a method of collecting data and Matrix method will be used in analyzing the media. This healthy lifestyle media is expected to engage the society, particularly among career women, to properly maintain their lifestyle in order to reduce the risk of disease and work productively.
\end{abstract}

Keywords: illustration, lifestyle, health, career women 


\section{PENDAHULUAN}

Wanita bekerja atau wanita karir banyak dijumpai di kota-kota besar, salah satunya di Kota Bandung. Wanita karir dianggap sebagai tren wanita masa kini yang mampu secara finansial. Menurut Badan Pusat Statistik Kota Bandung (2015) didukung dengan data, total penduduk usia produktif tahun 2015 sebanyak 72,04 persen dari total penduduk Kota Bandung dengan jumlah penduduk terbanyak kelompok umur 15-29 tahun dan 66,90 persen penduduk bekerja berstatus karyawan.

Menurut Dariyo (2003:10), secara umum, mereka yang tergolong dewasa muda (young adulthood) ialah mereka yang berusia 20-40 tahun. Menurut seorang ahli psikologi perkembangan, Santrock (1999), orang dewasa muda termasuk masa transisi, baik transisi secara fisik (physically trantition), transisi intelektual (cognitive trantition), serta transisi peran sosial (social role trantition).

Wanita karir memiliki peran ganda yaitu dalam pekerjaan maupun rumah tangga. Kegiatan multi-tasking, jam kerja, dan mengelola rumah tangga menyebabkan wanita karir rentan mengalami kelelahan, pusing, stres, dan perubahan berat badan, hingga gangguan menstruasi yang berakibat pada kesuburan. Resiko kesehatan tersebut dapat dialami apabila wanita karir kurang memperhatikan gaya hidup yang ia jalani.

Menurut Sutisna (2002:147) dalam bukunya Perilaku Konsumen dan Komunikasi Pemasaran bahwa gaya hidup secara luas didefinisikan sebagai cara hidup yang diidentifikasikan bagaimana orang menghabiskan waktu mereka (aktivitas), apa yang mereka anggap penting dalam lingkungannya (ketertarikan), dan apa yang mereka pikirkan tentang diri mereka sendiri dan juga dunia di sekitarnya (pendapat).

Pengertian gaya hidup menurut Departemen Kesehatan Indonesia (Depkes RI, 2007) adalah segala upaya untuk menerapkan kebiasaan yang baik dalam menciptakan hidup yang sehat dan menghindari kebiasaan yang buruk yang dapat menggangu kesehatan. Indikator gaya hidup sehat antara lain: perilaku tidak merokok, pola makan sehat dan seimbang, dan aktivitas fisik yang teratur (Depkes RI, 2002). Saat ini pemerintah juga sedang berupaya meningkatkan kesehatan masyarakat melalui Gerakan Masyarakat Hidup Sehat (GERMAS) yang meliputi kegiatan seperti: melakukan aktivitas fisik, mengonsumsi sayur dan buah, tidak merokok, tidak mengonsumsi alkohol, memeriksa kesehatan secara rutin, membersihkan lingkungan, dan menggunakan jamban (Depkes $\mathrm{RI}, 2016)$.

Informasi kesehatan umumnya ditemui pada media buku. Namun penggunaan bahasa atau penyampaian informasi menggunakan bahasa yang formal dan ilmiah. Menurut Rustan (2009:123), Buku berisi lembaran halaman yang cukup banyak, sehingga lebih tebal daripada booklet. Berbeda dengan booklet yang bisa dijilid dan steples atau bisa juga tidak dijilid karena hanya terdiri atas beberapa lembar, sedangkan pada buku penjilidan yang baik merupakan keharusan agar lembar-lembar kertasnya tidak tercerai-berai. Pada perancangan ini, pemilihan buku sebagai reminding dalam menjalani hidup sehat menggunakan ilustrasi sebagai dominan visualnya. Diharapkan dengan media buku dan media tambahannya mengenai kesehatan wanita karir, dapat 
membantu informasi lebih mudah diterima dan mengingatkan para wanita karir untuk menjaga gaya hidup sehatnya.

Menurut Kusrianto (2007:2) Desain Komunikasi Visual (DKV) adalah suatu disiplin ilmu yang bertujuan mempelajari konsep-konsep komunikasi serta ungkapan kreatif melalui berbagai media untuk menyampaikan pesan dan gagasan secara visual dengan mengelola elemen-elemen grafis yang berupa bentuk dan gambar, tatanan huruf, serta komposisi warna serta layout (tata letak atau perwajahan). Dengan demikian, gagasan bisa diterima oleh orang atau kelompok yang menjadi sasaran penerima pesan.

\section{METODE PENELITIAN}

Pengumpulan data menggunakan metode observasi, studi pustaka, wawancara serta kuesioner. Menurut Supardi (2006 : 88), metode pengumpulan data yang dilakukan dengan cara mengamati dan mencatat secara sistematik gejala-gejala yang diselidiki. Penulis melakukan observasi di beberapa perkantoran di Kota Bandung. Selanjutnya dalam mengumpulkan data dari studi pustaka, Penulis mempelajari buku-buku yang berkaitan dengan perancangan seperti buku mengenai hidup sehat seperti: Sehat itu Sederhana, Hidup Sehat Kinerja Melejit, dan buku yang berisi teori-toeri yang akan digunakan sebagai bagian dari bahan perancangan. Menurut Soewardikoen (2013:6), teori-teori yang digunakan untuk menganalisis bersumber dari pemikiran para ahli yang telah melakukan penelitian. Teori-teori yang dituliskan berdasarkan suatu cara pandang atau pemahaman tertentu yang kadang kala dapat berbeda dengan cara pandang ahli yang lain.

Wawancara adalah suatu bentuk komunikasi verbal jadi semacam percakapan yang bertujuan memperoleh informasi (Nasution, 2006:113). Penulis melakukan wawancara terstuktur kepada ahli bidang kesehatan yang berkaitan dengan permasalahan yang di bahas. Kemudian penulis juga mengumpulkan data dari kuesioner, suatu daftar pertanyaan mengenai suatu hal atau dalam suatu bidang, yang harus diisi secara tertulis oleh "responden", yakni orang yang merespon pertanyaan (Soewardikoen, 2013:25). Pada tahap ini, penulis membuat daftar pertanyaan ditujukan kepada target audience dari objek yang akan dirancang secara spesifik dengan media online. Perancangan buku ilustrasi kesehatan wanita karir ini, sumber data diperoleh dari artikel detikhealth, merupakan salah satu bagian dari portal berita detikcom yang memberikan informasi seputar kesehatan.

\section{HASIL DAN PEMBAHASAN}

Tanpa disadari aktivitas yang kurang sehat seperti tidak sarapan, pola makan dan tidur yang tidak teratur, merokok, menggunakan komputer terlalu lama, dan lainnya dapat menimbulkan kebiasaan baru yang buruk untuk tubuh. Pola hidup yang kurang terjaga dapat mendatangkan keluhan kesehatan pada siapa saja dan di usia muda sekalipun khususnya wanita karir. Pada sebagian wanita karir/produktif usia 22-29 tahun terlihat belum maksimal dalam menerapkan hidup sehat, sehingga timbul gangguan kesehatan yang menghambat aktivitas serta kurangnya buku informasi kesehatan khusus wanita 
karir di masyarakat. Hal inilah yang menjadi fokus pembahasan penulis dalam melakukan perancangan.

Hasil wawancara terstruktur pada 16 dan 24 Maret 2017 terhadap ahli kesehatan yakni Ibu dr. Marlina Sp. FK, selaku dokter umum dari Kementerian Dalam Negeri Jakarta Gym didapatkan data bahwa menurut Beliau, pekerja kantoran lebih banyak menghabiskan waktu di luar rumah, oleh karena itu penting untuk menjaga pola hidup sehat. Terutama dalam memperhatikan makanan yang di konsumsi, kebanyakan para pekerja kantoran tidak mempunyai waktu yang cukup untuk sarapan dan adapun sarapan yang sempat dikonsumsi merupakan menu yang tidak sehat seperti gorengan. Sarapan sebenarnya penting untuk nutrisi otak dan memberi energi awal untuk memulai aktivitas. Kemudian kurang memperhatikan duduk yang ergonomis sehingga dapat mengakibatkan low back pain, tingkat perokok aktif di lingkungan perkantoran yang masih cukup tinggi, penggunaan komputer, dan lainnya yang jika tidak diperhatikan kesehatannya, maka akibatnya akan dirasakan dalam jangka pendek dan jangka panjang. Beliau menyarankan bagi pekerja kantoran untuk rajin mengonsumsi buah dan sayur serta air putih.

Penulis juga melakukan wawancara dengan Bapak Teguh Prio Utomo selaku Club General Manager Gold's Gym, yang mengemukakan bahwa pekerja kantoran dengan office hour memiliki aktivitas yang cenderung diam sedangkan olahraga adalah gerak tubuh sehingga diperlukan keseimbangan karena pada dasarnya olahraga itu diperlukan setiap hari dengan durasi 10-30 menit, sebab memiliki kaitan dengan kesehatan jantung. Olahraga yang dapat dilakukan bagi pekerja kantoran yaitu body weight training seperti pull up dan sit up yang dapat disesuaikan. Menurutnya kebanyakan pekerja kantoran bukan tidak mempunyai waktu berolahraga, namun kurangnya motivasi untuk hidup sehat. Beliau juga mengatakan bahwa pentingnya untuk memilih menu sarapan tepat seperti mengkonsumsi pisang, fruit bar, jus, oatmeal dan cracker serta tidak disarankan untuk mengkonsumsi makanan berat seperti kentang dan nasi sebagai menu sarapan, karena tubuh bekerja berat untuk mencerna karbohidrat yang dapat membuat pekerja kantoran mudah mengantuk.

Dari hasil kuesioner yang disebarkan penulis pada 10-25 Maret 2017 kepada 16 responden wanita karir dengan lingkup kerja swasta, BUMN(Badan Usaha Milik Negara), PNS (Pegawai Negeri Sipil), maupun wirausaha dengan rentang usia 22-29 tahun menunjukkan bahwa sebagian wanita karir sadar akan resiko bekerja terhadap kesehatan, namun beberapa wanita karir masih melakukan aktivitas yang kurang sehat seperti durasi duduk sekitar 4-5 jam, waktu tidur malam yang kurang dari 8 jam, kurangnya olahraga ringan setiap hari, dan merasakan gangguan-gangguan kesehatan yang menghambat aktivitas. Hasil kuesioner juga memperlihatkan mengenai adanya kebutuhan tentang informasi kesehatan dan didapati jenis media buku yang paling banyak dipilih sebagai media yang dibutuhkan. 
Berdasarkan hasil analisis observasi, wawancara dan kuesioner serta matriks perbandingan antara buku kesehatan dengan judul "Sehat itu Sederhana" dan "Hidup Sehat, Kinerja Melejit", didapat bahwa rancangan buku mengenai kesehatan wanita karir akan mengacu pada buku "Sehat itu Sederhana" yang lebih persuasif dilihat dari tampilan visual dan gaya bahasa yang digunakan. Rancangan buku akan menggunakan ilustrasi, warna, tipografi serta layout yang sesuai dengan target audience agar dapat menarik dan mempertahankan minat baca.

\section{Konsep Desain}

Judul pada buku yaitu "Keep Healthy Ladies", dipilih dengan konsep pesan agar dapat mengajak dengan ramah dalam menjaga gaya hidup sehat. Penggunaan bahasa asing bertujuan memberikan kesan modern dan berwawasan luas, serta mencerminkan sosok wanita karir.

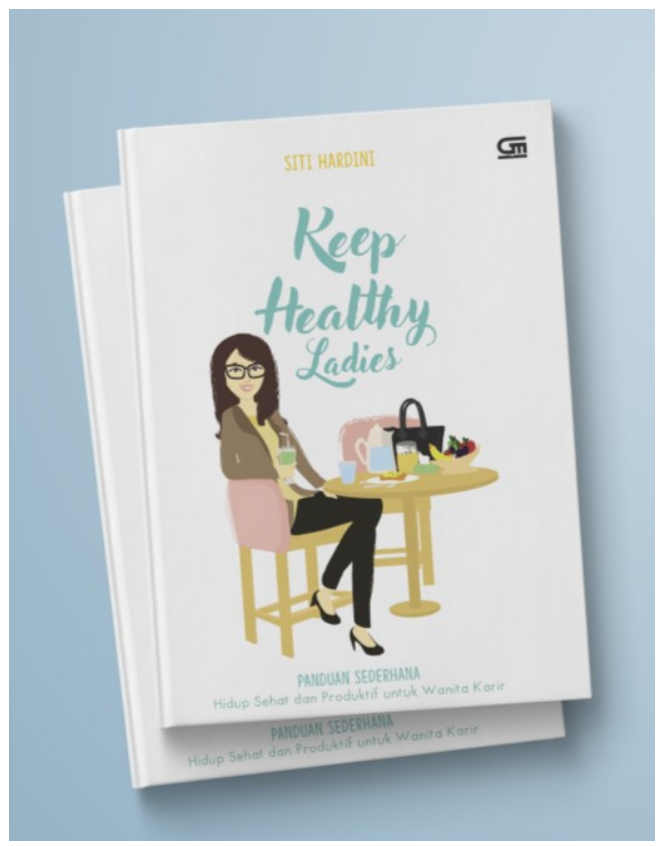

Gambar 1. Cover pada buku ilustrasi kesehatan wanita karir [Sumber: Hardini, 2017]

Isi buku disusun dengan paduan warna, agar informasi dapat tersampaikan dengan santai dan lebih menyenangkan. Penggunaan warna-warna cerah sebagai warna yang sesuai dengan tema kesehatan. Warna-warna cerah akan memberikan semangat dan membangun mood yang baik kepada pembaca. Penggunaan warna tersebut diharapkan dapat menarik perhatian wanita karir di sela-sela waktu bekerja. 

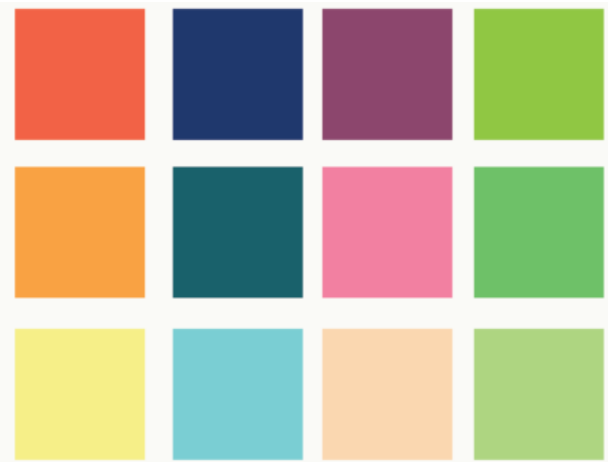

Gambar 2. Warna identitas visual pada buku ilustrasi kesehatan wanita karir

[Sumber: Hardini, 2017]

Pada perancangan media, penggunaan jenis huruf berperan pada keterbacaan yang akan mempengaruhi tersampainya pesan dengan baik kepada pembaca. Penggunaan jenis huruf pada keseluruhan halaman buku, poster maupun kalender di antaranya font Brush (font Adlery) dan sans serif (font Futurahandwritten dan font Congratulation Demo). Pemilihan font dimaksudkan untuk memberi kesan feminin dan modern. Pada penyusunan elemen desain, menggunakan layout dengan grid vertikal dua kolom, dan margin simetris dengan variasi pada grid sistem.

Konsep kreatif dalam perancangan media yakni media dikhususkan untuk para wanita karir dengan tampilan ilustrasi. Menggunakan hard cover pada bagian sampul buku dengan maksud agar berkesan lebih rapih dan eksklusif. Dominan warna putih pada cover untuk mencerminkan kebersihan dan kesehatan. Selain itu, ukuran buku dipilih berukuran A5 dengan tujuan ukuran buku yang lebih kecil mudah dibawa saat bepergian. Menggunakan ilustrasi flat desain dan tipografi yang feminin, warna-warna kesehatan, dan layout yang beragam dengan tujuan menarik minat baca.
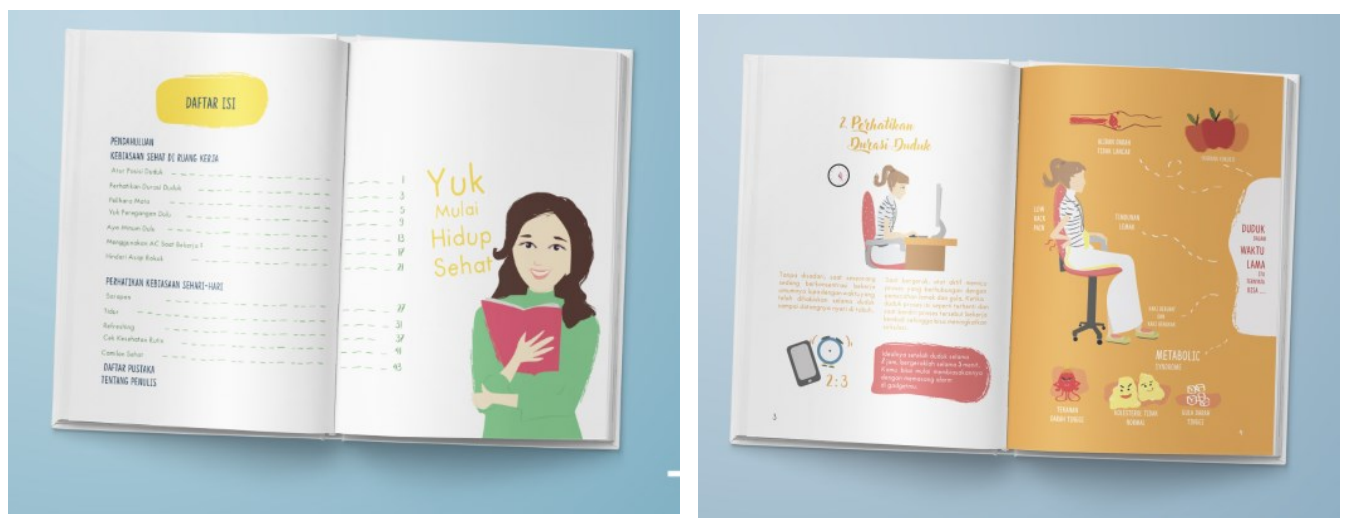

Gambar 3. Buku ilustrasi kesehatan wanita karir dengan ilustrasi flat desain

[Sumber: Hardini, 2017]

Melalui media buku, wanita karir lebih leluasa memperoleh informasi tanpa membutuhkan kuota internet maupun arus listrik. Selain itu, informasi dari buku cetak 
lebih mudah diingat untuk jangka panjang dibanding membaca via digital. Buku ilustrasi kesehatan memuat bahasan mengenai:

1. Kebiasaan sehat di ruang kerja

Membahas seputar pola duduk, kesehatan mata, peregangan, ajakan minum air putih, dan jauhi asap rokok serta kebiasaan sehat lainnya.

2. Perhatikan kebiasaan sehari-hari

Membahas seputar kebiasaan baik seperti pola tidur ideal, sarapan, cek kesehatan rutin, refreshing dan camilan sehat. Terdapat informasi tambahan mengenai menstruasi dan hamil pada halaman secret page.

Selain buku, terdapat media tambahan berupa kalender kesehatan berfungsi sebagai catatan kesehatan pribadi untuk digunakan sehari-hari berbentuk lembaran kertas tebal berjumlah 14 lembar dengan kayu sebagai holder.

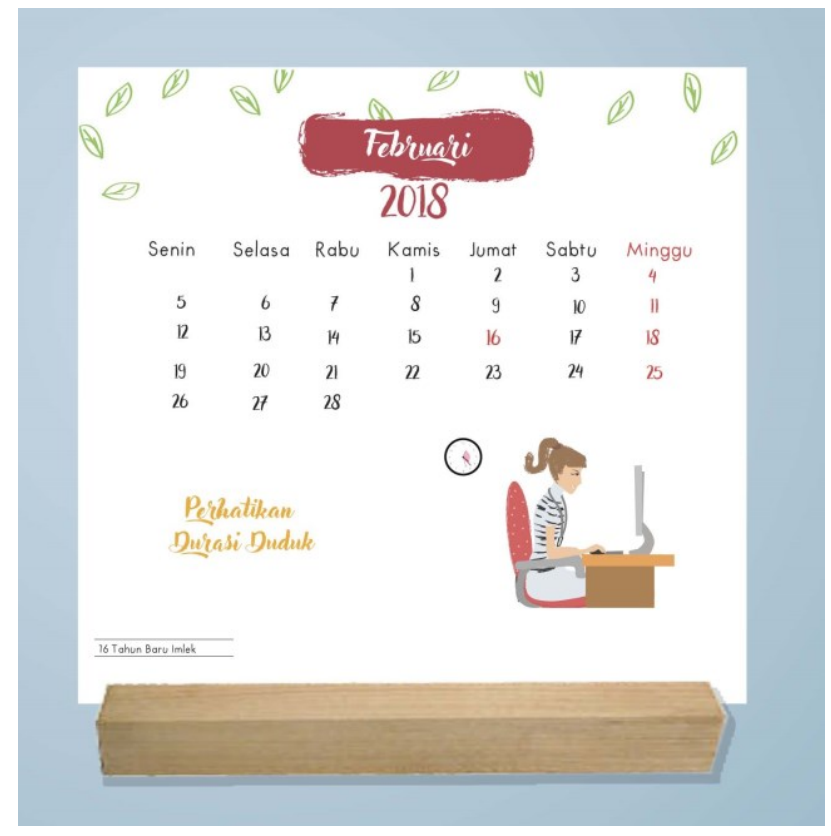

Gambar 4. Kalender ilustrasi sebagai catatan kesehatan pribadi

[Sumber: Hardini, 2017]

Dalam menyampaikan informasi kesehatan dengan nyaman dan ringan, maka digunakan elemen-elemen visual yang mampu menciptakan kesan tertentu agar dapat meningkatkan kesadaran mengenai kesehatan pada pembaca yaitu ilustrasi, warna, tipografi dan layout. Ilustrasi yang digunakan berkesan simple dan feminin. 

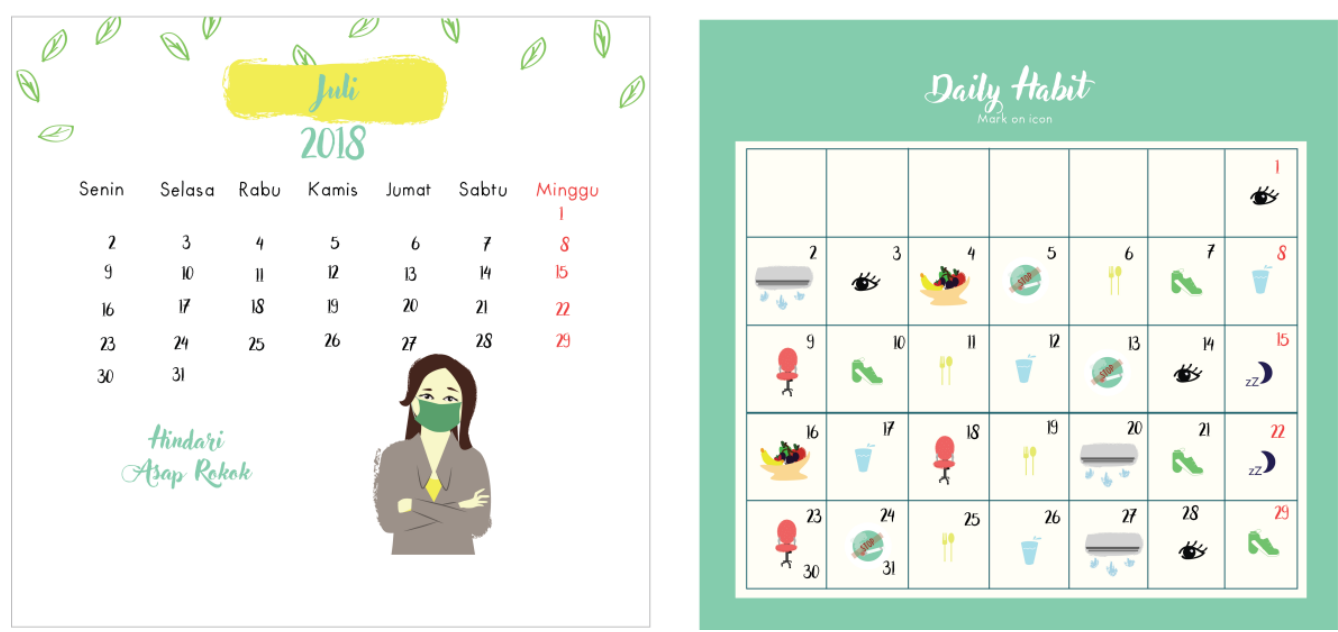

Gambar 5. Kalender ilustrasi tampilan depan dan belakang setiap lembar

[Sumber: Hardini, 2017]

Menurut Setiawan (2016) Ilustrasi diciptakan untuk menjadi bagian dari konsep rancangan, sehingga pesan yang diharapkan lebih mudah dipahami oleh masyarakat. Penggayaan visual ilustrasi yang digunakan yaitu persuasif, karena ilustrasi bertujuan untuk mengajak wanita karir memahami informasi kesehatan dengan mudah dan santai sehingga mendorong adanya tindakan. Selain media tambahan berbentuk kalender juga terdapat media poster di media online berjumlah 12 tampilan sebagai item pendukung dalam artikel yang akan diposting dan menambah minat pembaca.
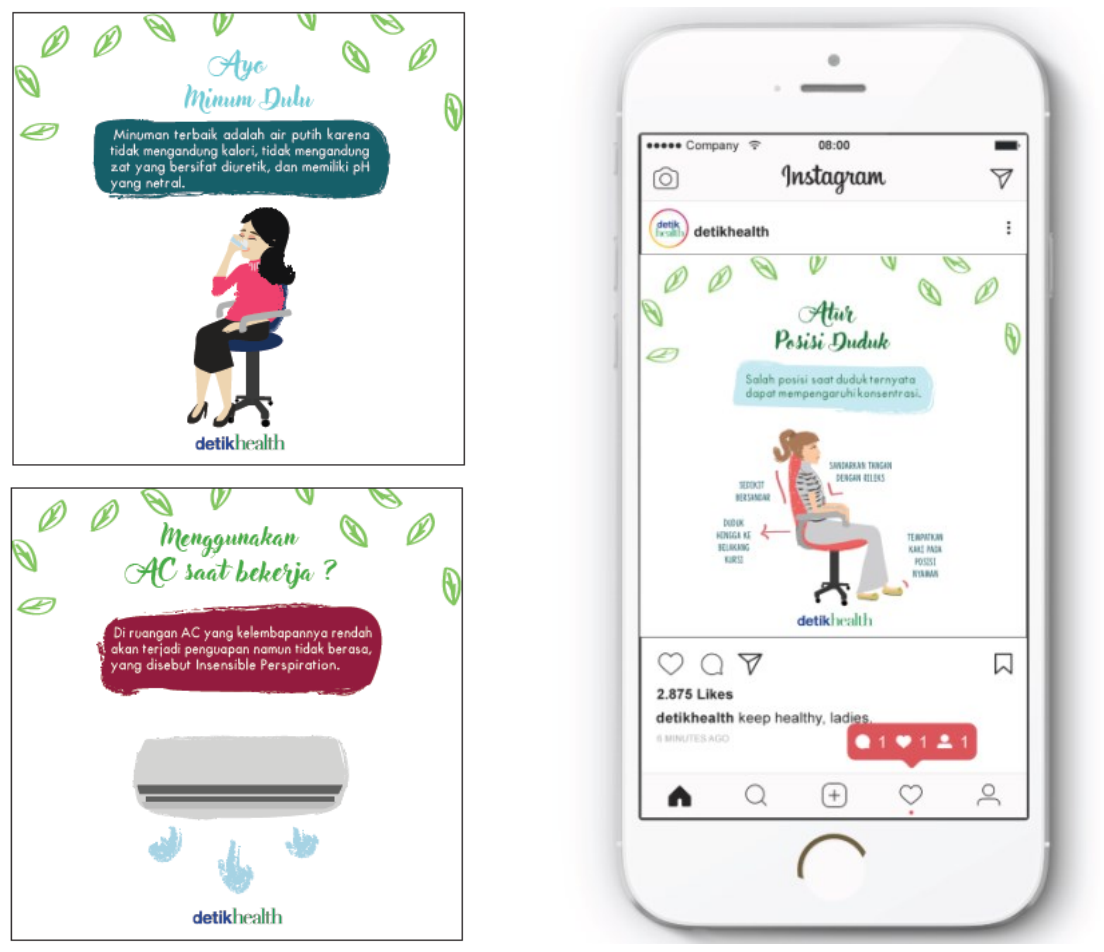

Gambar 6. (kiri) Tampilan poster dan (kanan) penerapan poster pada media online [Sumber: Hardini, 2017] 
Melalui media utama buku serta media tambahan kalender dan poster, diharapkan dapat meningkatkan kesadaran akan kesehatan.

\section{KESIMPULAN}

Perancangan buku ilustrasi kesehatan dibuat untuk mengajak wanita karir dalam menjaga gaya hidup yang sehat. Konsep perancangan disesuaikan dengan hasil analisis dari metode yang digunakan dan kriteria target sasaran. Berdasarkan target sasaran yakni wanita, maka perancangan media lebih menonjolkan elemen ilustrasi untuk mempertahankan mood baca yang berisi panduan-panduan sederhana yang dapat dilakukan wanita karir sehari-harinya. Dalam upaya mendorong aktivitas sehat, media kalender kesehatan sebagai media tambahan diharapkan dapat memotivasi target sasaran perancangan. Sedangkan poster Instagram diharapkan menjadi sumber informasi yang langsung kepada audience di dunia maya dimana sosial media menjadi salah satu gaya hidup wanita karir masa kini.

\section{DAFTAR PUSTAKA}

Dariyo, Agoes. 2003. Psikologi Perkembangan Dewasa Muda. Jakarta : Grasindo.

Kusrianto, Adi. 2007. Pengantar Desain Komunikasi Visual. Yogyakarta : Penertbit Andi. Nasution, S. 2006. Metode Reserch (Penelitian IImiah). Jakarta : Bumi Aksara.

Rustan, Suryanto. 2009. Layout Dasar \& Penerapannya. Jakarta : Gramedia.

Setiawan, A. 2016. Pencapaian Sense of Design dalam Perancangan Desain Komunikasi Visual. ANDHARUPA, 2(2), 207-217.

Supardi. 2006. Metodologi Penelitian. Mataram : Yayasan Cerdas Press.

Sutisna. 2002. Perilaku Konsumen dan Komunikasi Pemasaran. Bandung : Rosda Karya. 